\title{
Interactive comment on "Dynamics of Large Pelagic Ice Crystals in an Antarctic Ice Shelf Water Plume Flowing Beneath Land-Fast Sea Ice" by Craig Stevens et al.
}

\section{Anonymous Referee \#2}

Received and published: 24 November 2020

Summary: In McMurdo Sound, supercooled ISW containing suspended frazil/platelet ice crystals circulates out from the McMurdo Ice Shelf cavity. The frazil/platelet ice crystals can then be deposited beneath the land-fast sea ice in McMurdo Sound and contribute to the sea ice cover and amass into an unconsolidated sub-ice platelet layer (SIPL). The objective of this study was to develop the understanding of ISW outflow and boundary-layer processes influencing the SIPL by combining coincident observations of ocean currents, Ice Shelf Water properties, turbulence structure and frazil/platelet ice suspended in the water column beneath land-fast sea ice in McMurdo Sound. Individual ice crystal dimensions were measured, and ice crystal behaviour monitored in the boundary layer beneath the SIPL with camera observations and acoustic backscatter.

Printer-friendly version

Discussion paper 
Microstructure profiles were carried out to quantify turbulent mixing with the boundary layer. The observations were then related to background coincident ocean currents, water column properties and the tides. Three backscatter regimes identified were suggested to consist of 1) larger freely-floating platelet ice crystals, 2) intermediary size frazil to platelet ice crystals, and 3) a variable background backscatter assumed to be frazil ice suspension. Individual platelet ice crystals varied in size from $20-100 \mathrm{~mm}$.

Interactive comment

General Comments: ISW circulation processes and the deposition of frazil/platelet ice crystals at the interface between the ocean and SIPL are not well observed and thus not well understood. The processes influencing and forming the SIPL are thus very difficult to constrain. This paper presents important observations/analysis of coincident ocean properties, currents, boundary-layer processes and frazil/platelet ice beneath land-fast sea ice in a region of significant supercooled ISW outflow in McMurdo Sound. This is a rare dataset that provides much-needed information about the processes at play beneath the SIPL. However, I have several major comments that should be addressed before this paper is accepted to 'The Cryosphere'.

1) My main comment is that the research question is not clearly set up in the introduction and nor is it explicit in the abstract. This is a consistent thread throughout the paper and I had to read it several times before I could extract what this research aimed to address and why; why these specific measurements were made; and what their relevance was in the context of the research question and the greater motivation of the study.

The authors could address this by better framing and providing clarity on the motivations underpinning the research objectives. Additionally, spelling out why these specific measurements were made (especially for the non-expert in physical oceanography), what information they provide, and the significance and relevance of that information.

It would be useful to highlight the rarity of the observations and the importance of frazil/platelet ice size distributions/concentrations for understanding ISW plume dy-

Printer-friendly version

Discussion paper

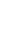


namics and for informing relevant models such as described in Hughes et al. 2014 and Cheng et al. 2019.

2) I find the 'Dirty Ice' sedimentation hypothesis contradictory. In the introduction, the authors state that sediment in the ice is partly marine in origin, and likely entrained in marine ice as it formed on the underside of the ice shelf and that this is evidence of significant ISW outflow from this part of the McMurdo Ice Shelf. They then suggest that the sediment is providing seed material for frazil ice nucleation and could be a factor in the SIPL distribution beneath the land-fast sea ice in McMurdo Sound. My understanding is that previous oceanographic, sea ice core and SIPL measurements have shown that the SIPL distribution is driven by significant ISW outflow in this part of the sound.

More to the point, there are no observations or any analysis of suspended sediment load/particulates or frazil ice nucleation in this study and though an interesting discussion, section 4.3 seems superfluous and not directly relevant to this work. I recommend that this section is removed or supported with evidence.

3) My final comment is that the paper should include a conclusion section providing a clear summary of the background context and motivation for the study, what was done and why, the main results and the significance and relevance of the findings. I struggled to extract the main findings of this work.

Specific Comments: (L refers to Line numbers)

Title: I suggest changing 'large pelagic' to platelet ice crystals

1) $L$ 10-11: Could you state why were these observations are presented and when they were collected?

Printer-friendly version

2) $L$ 23: I suggest changing 'fully grown" to larger platelet ice crystals of ? cm dimension.

Discussion paper

3) $L$ 23: What dimension are you referring to by 'Crystal scales'? 
4) L 31-32: I suggest changing to 'a potential driver contributing to.....

5) L 33-34: This sentence needs more detailed information.

6) L 37: Sustained melting and/or decay of what? This sentence needs a reference.

7) L 41-42: I do not fully understand this statement. Can you develop?

8) L 46-56: I suggest including the work of Cheng et al. 2019 and emphasising the importance of suspended ice crystal load for ISW plume dynamics and for understanding the processes that influence the SIPL.

9) L 65: I suggest changing camps to observations.

10) L 67: Hunkeler et al. 2015 and Hoppman et al. 2020 are not specific to SIPL studies in McMurdo Sound.

11) L 75-85: This paragraph should be developed to set up the research question better and to describe what was done and why.

12) L 89: 'over an ocean depth'

13) L 103: Frazer et al. 2020 is in review.

14) L 107: I suggest providing the dimensions of the ice hole.

15) L 110-111: Does this statement refer to platelet ice and frazil ice crystals? This needs clarification.

16) L115: Is there any previous evidence that it is a tightly interlocked matrix?

17) L127-131: Where is the echosounder pointing? Upward to the SIPL base? Is the beam $3 \mathrm{~m}$ wide at $25 \mathrm{~m}$ depth or at the SIPL base? It would be very useful to have an estimation of the field of view.

18) L139: What is meant by superficial appearances? Can you develop and better clarify this statement? 
19) L143-154: When were these measurements carried out and at what point on the tidal cycle?

20) L 165-172: Again, when were these measurements carried out and at what point on the tidal cycle?

21) $L$ 175-176: What indications are there that this be the result of buoyantly forced ISW plume?

22) $L$ 176-178: At what point on the tidal cycle were speeds of $0.1 \mathrm{~m} / \mathrm{s}$ observed and in what direction? Please see comments provided below on Figure 3. It would be useful to provide date and month in parentheses after Julian Day.

23) $L$ 180: I found the away and toward ice shelf convention confusing in the text and very difficult to interpret in Figure 3.

24) L 183: Is there a characteristic shape of platelet ice crystals?

25) L213-226: Can you be more specific about flow direction, point on the tidal cycle, temperature/salinity/backscatter changes and provide a date/time for each DOY.

26) $L$ 230: What is the relevance of the frequency structure?

27) $L$ 242: What is meant by $2-5 \mathrm{~m}$ undulation in SIPL underside? Where, when and how was this observed?

28) L 251: I suggest using profiles instead of realisations.

29) $L$ 261: 4 Discussion

30) L293: I suggest rewording the last sentence of this paragraph.

31) L307-308: The Hoppmann et al. 2015 and Hunkeler et al. 2015 studies were not carried out in McMurdo Sound.

32) L 380-405 and L 417-420: As above in the specific comments about the cooccurrence of the 'Dirty Ice' and SIPL distribution. 
33) L424: Richter et al. 2020 is in review.

34) L424-432: This paragraph could be developed further to provide a more substantiated context and broader outlook for this study.

35) L 427: I do not understand this statement.

Technical Comments: 1) The Frazer et al. 2020 and Richter et al. 2020 studies are currently in review.

\section{Specific Comments on Figures}

Figure 1: I suggest combining a and $\mathrm{c}$ into one figure and masking out the land. A MODIS optical image showing the land-fast sea ice conditions at the time of the field campaign would be more informative as would stating the date/month of acquisition.

Figure 2: At what point on the tidal cycle was this profile taken? And what are the DOY to relate to Figure 3 ?

Figure 3: I suggest moving a, b, c and d labels to top LH corner and put in parentheses; to make $y$-axis of tidal height larger. How was tidal height modelled? Please clarify convention for directions in $a$ and $b$.

Figure 6: State DOY to relate to Figure 3.

Figure 12: Modify to account for changes to section 4.3 etc.

Suggested reference: Cheng, C., Jenkins, A., Holland, P. R., Wang, Z., Liu, C., and Xia, R.: Responses of sub-ice platelet layer thickening rate and frazil-ice concentration to variations in ice-shelf water supercooling in McMurdo Sound, Antarctica, The Cryosphere, 13, 265-280, https://doi.org/10.5194/tc-13-265-2019 , 2019. 